\title{
Smart cities: the state-of-the-art and governance challenge
}

\author{
Mark Deakin
}

\section{Correspondence:}

m.deakin@napier.ac.uk

School of Engineering and Built Environment, Edinburgh Napier University, 10 Colinton Road,

Scotland EH10 5DT, UK

\begin{abstract}
Reflecting on the governance of smart cities, the state-of-the-art this paper advances offers a critique of recent city ranking and future Internet accounts of their development. Armed with these critical insights, it goes on to explain smart cities in terms of the social networks, cultural attributes and environmental capacities, vis-a-vis, vital ecologies of the intellectual capital, wealth creation and standards of participatory governance regulating their development. The Triple Helix model which the paper advances to explain these performances in turn suggests that cities are smart when the ICTs of future Internet developments successfully embed the networks society needs for them to not only generate intellectual capital, or create wealth, but also cultivate the environmental capacity, ecology and vitality of those spaces which the direct democracy of their participatory governance open up, add value to and construct.
\end{abstract}

Keywords: Smart cities; City ranking; Future Internet developments; Triple Helix; ICTs; Social networks; Culture; Environment; Regional innovation systems;

Participatory governance and knowledge economy

\section{Multilingual abstracts}

Please see Additional file 1 for translation of the abstract into the five official working languages of the United Nations and Portuguese.

\section{Background}

This paper takes the opportunity to reflect upon the concerns surrounding the governance of smart city developments. In particular, the suggestion from Hollands (2008) that such issues have more to do with cities meeting the corporate needs of marketing campaigns than participatory governance which is required for them to be smart. Working on the assumption that any attempt to overcome such concerns means shifting attention away from the needs of the market and towards the direct democracy of participatory governance, this paper begins to address such matters by developing a more critically insightful understanding of the subject.

\section{Methods}

In developing such an understanding, the paper bases this process of knowledge production not on conjecture surrounding either 'smart city ranking', or 'future Internet' accounts of their development but legacy of research carried out into the informational basis of the communication systems smart cities embed. That legacy which in turn leads away from the competitiveness of smart city ranking and business logic of future Internet development and towards an examination of the social capital, not only critical in underpinning the 
informational basis of their communication systems, but insightful in revealing the wider cultural and environmental significance of the intelligence supporting the creation of wealth.

In cutting across the social capital, cultural attributes and environmental capacities of smart cities, the representation that surfaces from this Triple Helix-inspired account differs markedly from those advanced either by the smart city ranking or future Internet versions of their development. In this respect, the Triple Helix-inspired account of smart cities advanced in this paper argues that such 'ranking' and 'Internet'-centred explanations are insufficiently grounded in the intelligence which not only underlies their process of wealth creation but that also surfaces to regulate the standards by which communities participate in the governance of such developments.

These are the governance challenges this paper examines, because they represent the top-level issues to be bottomed out, either by way of accounting for the intelligence smart cities embed, or through an examination of the innovation systems they found. In particular, the intelligence they embed and innovation they found not on the basis of any smart city ranking or future Internet development but in relation to the creative attributes and environmental capacities of a modified Triple Helix model.

\section{State-of-the-art}

The state-of-the-art on these governance challenges has already been extensively reviewed by Deakin (2013) as a retrospective on the research undertaken, reported on and disseminated under the SmartCities project (http://www.smartcities.info/). This review of the literature identifies three emerging accounts of the governance challenges surrounding smart cities. Listing them chronologically, they account for them by way of: smart city rankings, future Internet developments and through a Triple Helix model of smart cities. They all claim to capture something significant about the governance challenges and offer insightful accounts of smart cities.

\section{Smart city rankings}

For Giffinger et al. (2008), smart city rankings offer the means for cities to market their attributes and use such performance indices as a means to 'outsmart' one another. In this examination of smart cities, standard city ranking procedures are recast by prefixing terms like: economy, people, governance, mobility, environment and living with the word smart and attaching a set of indicators to account for their factor performances. These factor performances include hard and soft attributes, such as: innovative spirit, entrepreneurialism, economic image and trademarks, creativity, cosmopolitism and open-mindedness. Hard and soft attributes Giffinger et al. (2008: 4) suggest offer a measure of 'smartness' because they: imply the implicit or explicit ambition/intention [for the city] to improve its performance'.

As a clear example of what Hollands (2008: 302-306) refers to as: measures that do more to meet the corporate needs of leading marketing campaigns than the social, cultural and environmental requirements of their citizens; this is not a line of enquiry those with a particular interest in the governance challenge smart cities pose take further. For putting the questions surrounding the 'complex causalities of such factors' (Giffinger et al. 2008: 13) aside and in particular, their specific weightings; those seeking a critically informed understanding of such performances prefer instead to begin with the more insightful definition of smart cities offered by Caragliu et al. (2011: 70). That definition which suggests a city may only claim any such status, not when it performs as a smart economy, with smart people and a smart governance system, but: 
'when investments in human and social capital and traditional (transport) and modern (ICT) communication infrastructure fuel sustainable economic growth and a high quality of life, with a wise management of natural resources, through participatory government.'

As those advocating future Internet accounts note, while still performance-based, this definition is particularly valuable for the simple reason that its holistic nature nicely balances the different social, cultural and economic components of smart city developments, without pre-judging either the weight or significance of any specific component. Perhaps more significantly, it also serves to emphasise the role ICT-related developments play in sustaining economic recovery, underpinning social welfare and supporting cultural health and well-being by highlighting the Internet as an enabler of participatory government.

Given these qualities do offer a critical insight into the 'complex causalities of such factors', it is perhaps not surprising to learn that it is this less directly competitive and more socially-inclusive, cum cultural and environmental definition, which is also adopted by those advocating a Triple Helix-inspired account of smart city developments. This is because as a normative statement, the purposeful and action-orientated nature of the definition also goes some way to overcome one of the methodological ambiguities of the smart city ranking approach: in short, the real possibility that any such performance may be the result of actions which are only 'implicitly' related to these developments and not the outcome of some consciously pursued strategy.

This ambiguity is particularly significant for the smart cities ranking system as many of the cities which perform well do not either market themselves as smart, or have the corporate strategies to support any such claim. The ambiguity of this ranking tends to suggest: 'smartness' is not only something which it is difficult to provide an acceptable performance-based definition of but also offer an explanation for, even by those cities that are awarded with such a status. This in turn resulting in the unfortunate situation whereby the 'smartness of cities' is represented as something which to some extent is unintelligible and a state-of-being that lies beyond reason.

In contrast to this, future Internet and Triple Helix-inspired accounts both assume that it is possible to know what 'being smart' means, be conscious of the attributes and capacities which grant cities such a status, learn from these developments and share the critical insights they offer with others. This is because they understand such developments to be the product of innovations within existing system(s) that are intelligible in the sense which they are purposefully designed to achieve such a status, both by way of and through a pre-conceived set of actions standing to reason.

\section{Future Internet developments}

The future Internet thesis is advanced by Schaffers et al. (2011) and Komninos et al. (2013). In setting this out, Schaffers et al. (2011: 431) propose:

'Cities nowadays face complex challenges to meet objectives regarding socio-economic development and quality of life. The concept of 'smart cities' is a response to these challenges. [We] explore 'smart cities' as environments of open and user-driven innovation for experimenting and validating Future Internet-enabled services. Based 
on an analysis of the current landscape of smart city pilot programmes, Future Internet experimentally-driven research and projects in the domain of Living Labs, common resources regarding research and innovation, can be identified that can be shared in open innovation environments. Effectively sharing these common resources for the purpose of establishing urban and regional innovation ecosystems requires sustainable partnerships and cooperation strategies among the main stakeholders'.

As Schaffers et al. (2011) go on to state, the first task that cities must address in becoming smart is to cultivate a rich environment of broadband networks which support digital applications. This includes the following:

- The development of broadband infrastructure combining cable, optical fibre and wireless networks, offering high connectivity and bandwidth to citizens and organisations located in the city;

- The enrichment of the physical space and infrastructures of cities with embedded systems, smart devices, sensors and actuators, offering real-time data management, alerts and information processing.

As Schaffers et al. (2011) go on to stress, the creation of applications enabling data collection and processing, web-based collaboration and collective intelligence in cloud computing and the emerging Internet of Things, is the first task to consider. This is because for Schaffers et al. (2011), these are the only technologies that can assure economies of scale in infrastructure provision, standardisation of applications and turn-key solutions. The second task they identify is that of initiating large-scale innovation processes for the creation of applications able to run with and improve every sector of activity, city cluster and infrastructure. Here all city activities and utilities are characterised as innovation ecosystems where citizens and organisations participate in the development, supply and consumption of resources.

As they point out, in creating this rich environment for initiating large-scale innovation, two different layers of collaboration come into play. The first layer relates to collaboration within the innovation process, which is understood as ongoing interaction between research, technology and application development. The second layer concerns collaboration at the territorial level, driven by urban and regional development policies that aim to strengthen innovation. That layer of territorial collaboration which Komninos et al. (2013) suggest builds on Porter's (1990) concept of national competitive advantage and begins to assemble the innovation systems associated with the mode 2 thinking Freeman (1995) develops.

Following this line of reasoning, Komninos et al. (2013) propose the urban value creation system advocated by the European Network of Living Labs (ENoLL), which can be considered as being shaped by four determinants:

- Physical and immaterial infrastructure;

- Networks and collaboration;

- Entrepreneurial climate and business networks;

- Demand for services and availability of advanced end users. 
This value creation in turn translates into the innovation system set out in Figure 1.

\section{The Triple Helix model of smart cities}

The basis for this account is set out by Leydesdorff and Deakin (2011) in their paper on the Triple Helix of smart cities. This brings to light how the Triple Helix model of smart cities provides the opportunity to study the knowledge base of communities in terms of civil society's support for the cultural and environmental development of their innovation systems (also, see Deakin and Leydesdorff, 2013).

\section{The schema}

In this schema, cities are considered to be densities in networks among at least three relevant dynamics: that is, in the intellectual capital of universities, industry of wealth creation and participatory governance of the democratic system which forms the rule of law. The effects of these interactions are in turn understood to generate spaces where the informational basis of communication systems are exploited to bootstrap the notion of smart cities and exploit the opportunities future Internet developments offer to not only generate intellectual capital but also create wealth. That is to say, generate intellectual capital and create wealth as much from the cultural attributes and environmental capacities of knowledge production, as the economic transactions which in turn relate such ICT-related developments to their emerging regional innovation systems.

This captures what perhaps best distinguishes future Internet accounts of smart cities from Triple Helix models of their development. In the sense that: while future Internet accounts are content to account for the economic attributes and capacities of ICTrelated developments, advocates of the Triple Helix model seek to involve the cultural attributes and environmental capacities in any explanation of smart city development. This is not to suggest advocates of the Triple Helix currently offer a particularly insightful account of what cultural and environmental attributes contribute to the

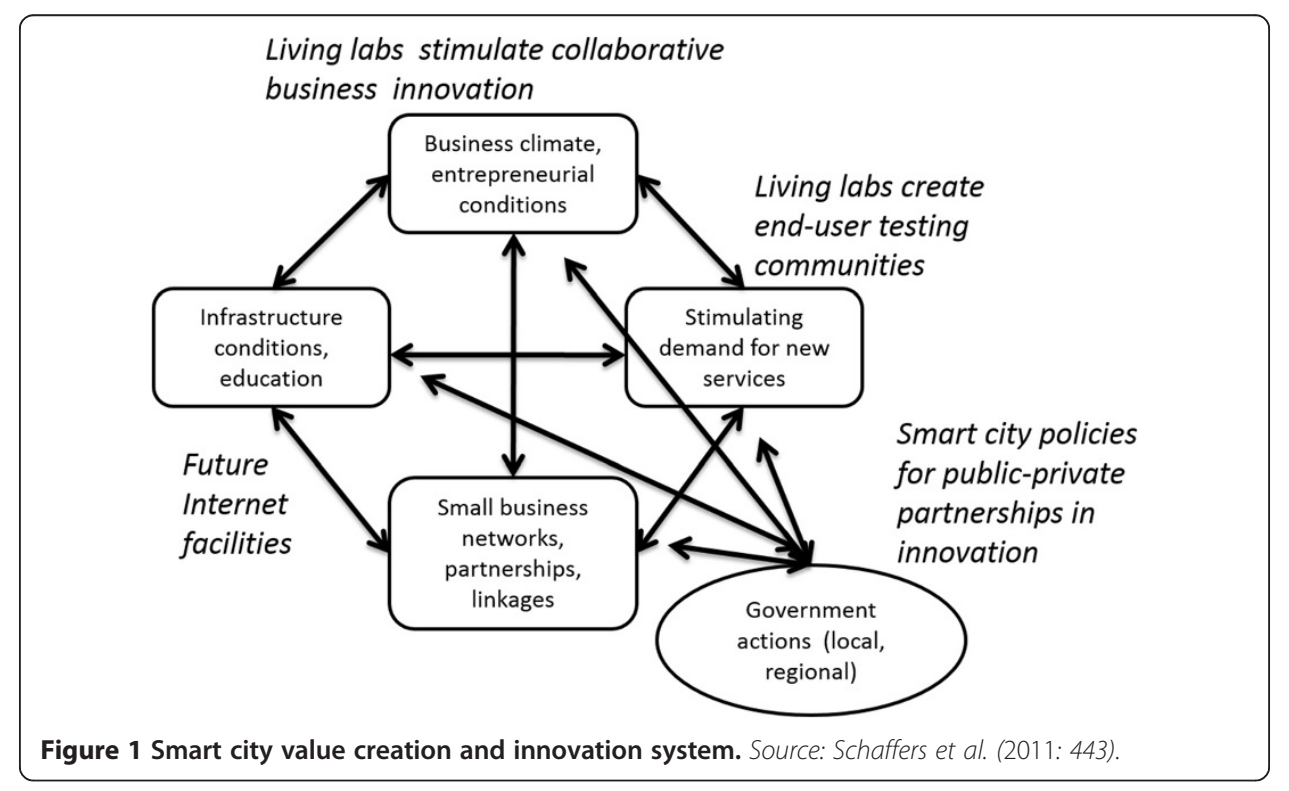


governance of such ICT-related developments. For while the Triple Helix is the only model which is explicit about the incorporation of governance-related issues into any such system of knowledge production, accounts of the schema offered by Etzkowitz (2002, 2008) tend to restrict such accounts to the rule of law and standards this lays down for the regulation of intellectual property rights.

\section{Governance}

It is in the interests of loosening the tight grip which the rule of law currently has over the Triple Helix and switching attention towards policy, corporate strategy and leadership that what follows reviews the whole question of governance in the model's dynamics (Deakin, 2010a, Deakin, 2010b). The outcome of this reflection is captured in the following quote from Leydesdorff and Deakin (2011: 61) and in relation to the governance issues surrounding their neo-evolutionary model of smart cities. That is, in terms of the policies, corporate strategies and academic leadership surrounding the governance of cities and whose intellectual capital is founded on a process of wealth creation which is smart because it rests on participatory governance. As they state:

'The capacity to process this transition reflexively, that is, in terms of translations, [in this instance, from creative, to intelligent and as part of the transition to smart cities] marks this development as something which takes us beyond the dismantling of national systems and construction of regional advantages. Using this neo-evolutionary perspective of the Triple Helix model, it can be appreciated that cultural development, however liberal and potentially free, is not a spontaneous product of market economies, but the outcome of policies, academic leadership qualities, and corporate strategies, all of which need to be carefully constructed, pieced together, and articulated before management can govern over them'.

It is the construction of these policies, academic leadership qualities and corporate strategies that Lombardi et al. (2011) explore with regard to the four visions of smart cities drawn from the 'Urban Europe' Joint Programme Initiatives (Nijkamp and Kourtit 2011). As Lombardi and Giordano (2012) state, these policy visions are of the following:

- Connected city (smart logistic and sustainable mobility)

- Entrepreneurial city (economic vitality)

- Liveable city (ecological sustainability)

- Pioneer city (social capital and participatory governance)

It is Cruickshank (2011) and Deakin et al. (2011) who take these policy visions further. This is achieved by developing an operational model of smart cities, whose Triple Helix is based on the social capital of the pioneer city, networking of the intelligence this generates, wealth it creates and in turn cultivates as an environment for participatory governance.

Unlike earlier versions of the Triple Helix, the pioneering version of the model set out in Figure 2 does not rest on the configurative logic of any 'overlapping' interests between university, industry and government. This version of the Triple 
Helix is instead based on the informational basis of the communication system emerging from the reflexivity of smart cities and stabilisation their development offers. For unlike existing representations of the Triple Helix, the transnational regime of knowledge production, intellectual capital and wealth creation this model is founded on does not rest with the distinction between either the fundamental or strategic research of scientific and technical development but instead with the informational basis and communication systems of the so-called 'third mission' agenda. That third mission agenda which is government-led and like university and industry targets the generation of intellectual capital and creation of wealth, but not in this instance from either scientific or technical innovations but rather from the social networks, cultural attributes and environmental capacities that have tended to fall out with the fundamental and strategic concerns which pre-occupy their counterparts.

The reason for this focus on the government-led third mission research agenda is simple. It is because of the following:

- A study of the intellectual capital published as academic papers by scientific and technical communities in Montreal, Edinburgh and Glasgow reveals there to be no direct relationship between either the fundamental or strategic research of these pioneer cities and those which do not claim to be smart (Leydesdorff and Deakin, 2011).

- An analysis of patents registered by universities and industry in 13 further cities in the North Sea region of Europe also found there to be no direct relationship between those claiming to be smart and others which choose not to define themselves in such terms (see Lombardi et al. 2011).

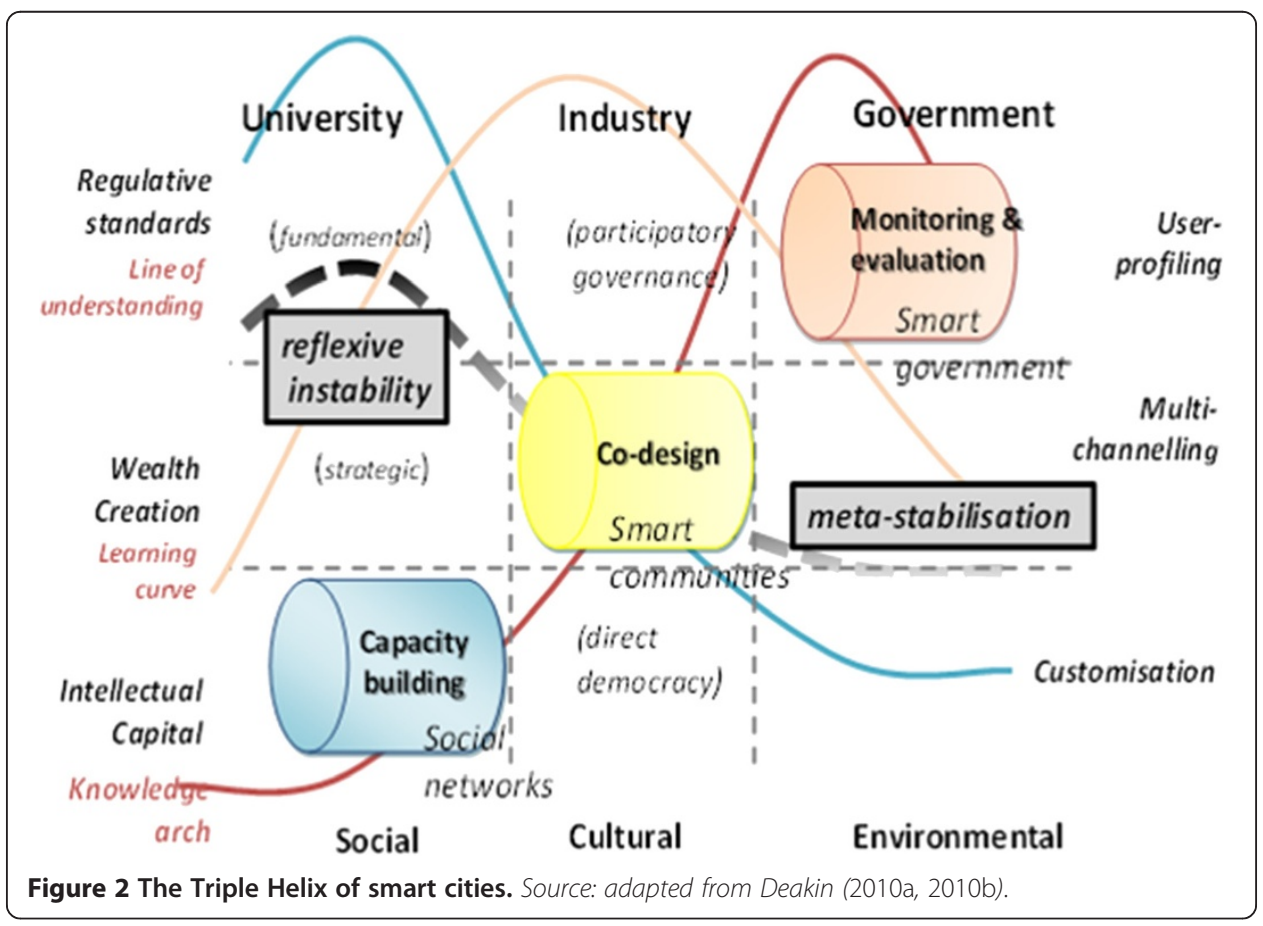


Together, such findings suggest that in their current state, cities which claim to be smart fail the primary and secondary tests traditionally applied to measure the intensity of knowledge production: namely, underlying scientific and technical publications and supporting patent registrations. The absence of such measures, in turn, tending to suggest any explanation for the development of smart cities is not to be found in either fundamental or strategic accounts of their innovation systems but elsewhere.

In the interest of searching out this 'elsewhere', the following turns attention away from scientific and technological-based accounts of such ICT-related developments and instead towards the intellectual capital of social networks, whose underlying cultural attributes and environmental capacities surface as the third mission agenda of this government-led venture into wealth creation. That agenda, which up till now, has been of little interest to either university or industry because the prevailing academic wisdom has considered the cultural and environmental value of this third mission (into networks, attributes and capacities) to be a venture neither fundamental enough, nor sufficiently strategic to warrant particular attention (Deakin, 2010a, 2010b).

The following challenges this academic wisdom and assumption which states that such networks, attributes and capacities do not warrant attention from either university, or industry. It suggests: what makes the innovation systems of certain cities smart, defines them in this way and allows them to stand out, is the growing tendency for a certain type of academic leadership to consider the embedded intelligence of these networks, attributes and capacities as something of strategic value. Something of strategic value for the reason:

- They open up the opportunity for communities (academic-led, business-orientated and citizen-centred alike) to learn about how their participation in the governance of scientific and technical innovations in the telecommunications sector can leverage a process of wealth creation mutually advantageous to both university and industry (Deakin and Al Waer, 2011; Deakin, 2012a, 2012b);

- That in leveraging such a mutually advantageous process of wealth creation, government involves itself with and participates in a 'third mission' agenda which is not exclusively proprietary, but communal. In that sense wrapped up with the policies, corporate strategies and academic leadership of ICT-related developments which are purposefully designed to be socially-inclusive by 'reaching out,' 'working alongside and in partnership' with their counterparts (Deakin and Al Waer, 2011; Deakin, 2012a, 2012b, 2012c).

Figure 2 meets the socially inclusive expectations of this so-called participatory governance. It not only configures but also assembles the informational basis of a communication system able to overcome the 'statesman', 'corporatist' and 'laissez faire' idioms of knowledge production. Here the 'overcoming of these legacy systems' is achieved by founding the informational basis of this communication system, not on either fundamental, or strategic accounts of their ICT-related developments, but instead on the intellectual capital embedded in the social networks, cultural attributes and environmental capacities of this third mission agenda.

This is how the Triple Helix represented in this model of smart cities neither overrelies on the reflexivity of knowledge production under the political economy of the 
nation-state (statesman and corporatist idioms), nor on the intuition of cultural creativity within the ongoing internationalisation of neo-liberal agendas (laissez faire), but instead localises the contemporary breakdown of the former and territorial expansion of the latter in the wealth created from the ICT-related developments reported on.

This process of wealth creation manifests itself in the development of electronically enhanced services, whose customisation of the networks, cultural attributes and environmental capacities is smart because it leads cities to co-design these ICT-related developments as a set of business-to-citizen applications (see Figure 2). In this instance, as a set of business-to-citizen applications, whose multi-channel access and userprofiles have the attributes and capacities that communities need to participate in the governance of these developments and for cities to be smart in opening up the spaces which are required for the intellectual capital embedded in this process of wealth creation to act as an exercise in direct democracy (Deakin, 2012a, 2012b).

Such a Triple Helix model of smart cities not only allows participation to serve as a means to reintegrate government back into the contemporary state of knowledge production but also gets beyond the corporate marketing campaigns of 'smart city ranking' and the more anthropocentric line of reasoning associated with ENoLLs 'Living Lab' account of ICT-related developments. For rather than following the line of reasoning which projects the knowledge economy into the vitality of the 'innovation ecosystems' surrounding these emergent spaces, this Triple Helix inspired model does something else. This something else being the 'overlaying' of the communication system onto cities that pioneer such ICT-related developments and which in turn present them as a mirror image of everything which has come to symbolise 'being smart' by setting out:

- The communication system that embeds the ICT-related developments needed for such forms of social capital to underpin the networks upon which their intelligence stands (Deakin, 2011a, 2011b);

- The attributes and capacities which communities in turn require to open up the spaces that make it possible for their participation in the third mission agenda of this government-led venture to create wealth (Deakin, 2012a);

- The co-design of business-to-citizen applications, multi-channel access and user profiles that provide communities with the intelligence which is needed for them to participate in the governance of these ICT-related developments alongside university and industry and open up the spaces required to create wealth from such exercises in direct democracy (Deakin, 2012b).

The significance of how this critical synthesis of the underlying legacy systems also surface as a reconciliation for the reflexive instability and meta-stabilisation, all of these innovations are equally wrapped up in, i.e. as a dynamic process of transnational development and global change, is perhaps best captured by Caragliu et al. (2013). For symbolized in terms of the outcomes their investigation into such development and change generate, Caragliu, et al. (2013: 186) suggest this:

'Show [s] consistent evidence of a positive association between urban wealth and the presence of a vast number of creative professionals, a high score in a multimodal accessibility indicator, the quality of urban transportation networks, the diffusion of 
ICTs (most noticeably in the e-government industry), and, finally, the quality of human capital. These positive associations clearly define a policy agenda for smart cities, although clarity does not necessarily imply ease of implementation.'

Caragliu et al. (2013) also go on to suggest that if government policies towards smart cities are going to be successful in maintaining the types of positive associations, future Internet accounts assume them to be the harbingers of, there shall not only have to be a deep restructuring of the ICT sector, so as to include transport, energy, water and waste, but also complete rethinking of the communication infrastructure.

\section{The metrics}

Reviewing the metrics of smart city developments, Kourtit et al. (2013) reiterate many of the debates found elsewhere on the embedded intelligence of social networks, cultural attributes and environmental capacities of smart cities, but go on to advance on these by:

'adding another unifying factor to the analysis, namely urban environments and their contour conditions. While it is accepted by the authors of this [paper] that knowledge is created by the interplay and relations of the three traditional helices interacting within regional innovation systems, with the Advanced Triple Helix model we propose, its accumulation is enhanced by way of interaction with urban environments and through their contour conditions. [For] contour conditions not only contribute to the creation of the intellectual capital within cities willing to achieve a 'smart'status (in the sense of contributing to wealth creation); they also influence the setting of the standards Government draws upon to regulate this regional innovation system.'

This, as Lombardi et al. (2012) and Kourtit et al. (2013) both suggest, is significant because such a modified representation of the Triple Helix underlines the importance of analysing the multitude of cultural attributes and environmental capacities when assessing the performance of smart cities (see Figure 3). In particular, the importance of evaluating this performance as part of an analytical hierarchy process (AHP) that serves to extend both the form and content of the Triple Helix which is set out in Figure 2. This modification of the Triple Helix involves the following:

- Translating the traditional Triple Helix schema into a set of metrics able to approximate the smartness of cities;

- Setting out the six dimensions of the advanced Triple Helix;

- Laying down the indicators for measuring the smartness of cities;

- Carrying out a principal component analysis (PCA) representing the relationship between the advanced Triple Helix and smartness of cities as a performance measurement.

In extending the multidimensional nature of the intelligence embedded in the cultural attributes and environmental capacities set out in Figure 2, the subsequent configuration (set out in Figure 3) serves to formalise the advanced Triple Helix model of smart cities and content of this future internet-based performance measurement. 


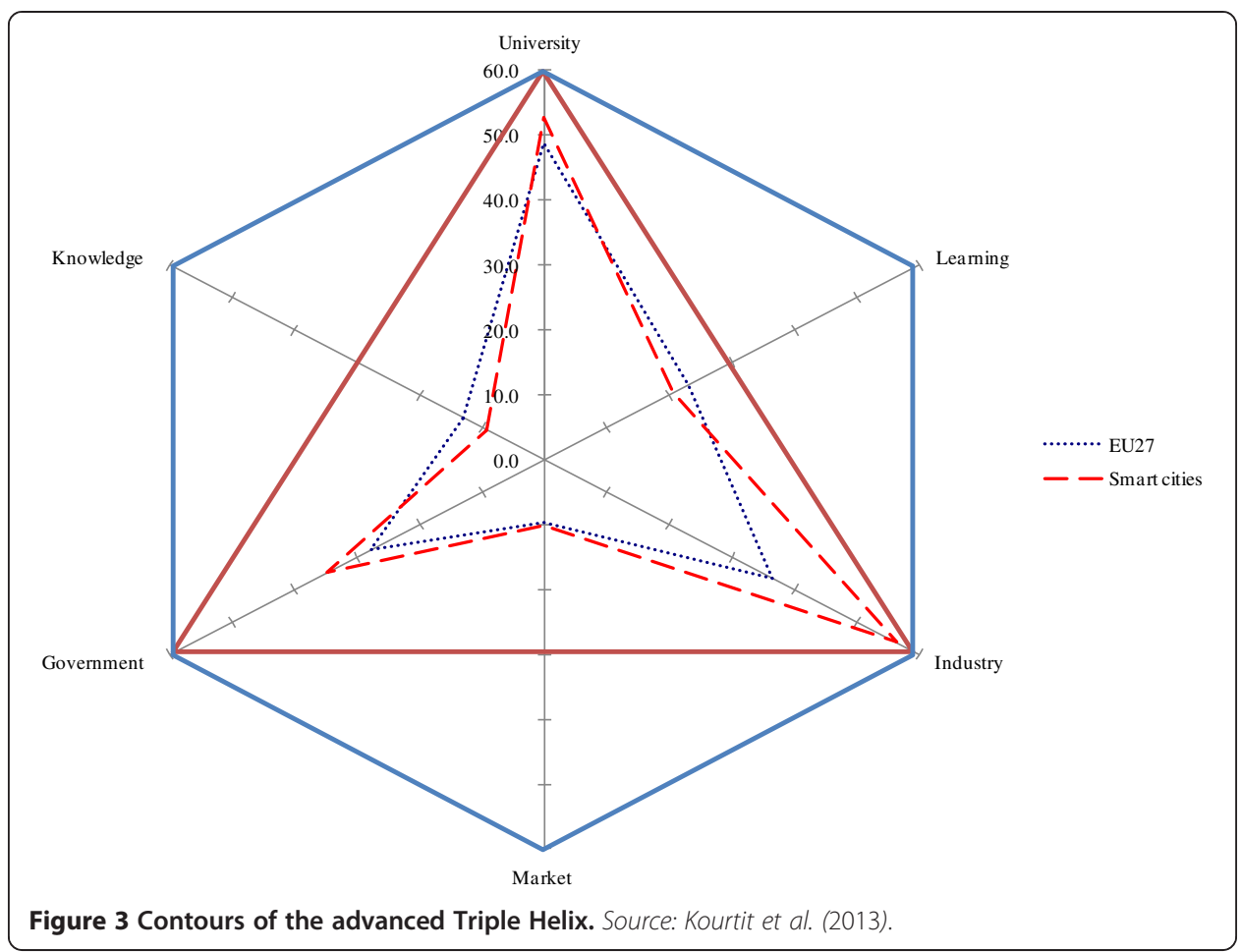

Notes:

1. With respect to the traditional Triple Helix, the smart cities of this regional innovation system are above the EU average. As such they have a higher proportion of young adults engaged in higher education, a higher share of labour force in the government sector and a higher intensity of firms per population.

2. However, while Smart Cities match the average EU performance in terms of the market, they slightly under-perform in knowledge and learning when compared against the EU average. This suggests that, while the 9 cities in this sample are indeed moving in the right direction, there is still room for improvement.

Within the contours of the advanced Triple Helix, smartness and relative positioning of cities do not necessarily coincide. In order to make this statement evident, Kourtit et al. (2013) compile a performance index within the advanced Triple Helix based on the PCA of indicators assembled to assess the smartness of cities. Here the indicators of smartness are defined as percentage of households with Internet access at home and proportion of households with broadband access and are measures which link the content of Figures 2 and 3 to the form that is represented here. This is because of the significance 'internet access at home' symbolises for society and the ICT-related developments this in turn networks as the cultural attributes and environmental capacities of smart cities, both by way of Web2.0 services and through broadband access. 
As Kourtit et al. (2013: 206) state, the noticeable outcome of this analysis is that:

'no city scores high with respect to both indicators, highlighting a potential direction for future improvement. In quadrant II we observe cities scoring high in terms of ICT endowment, but relatively worse in terms of structural innovation-oriented characteristics. In quadrant IV the opposite happens, with cities showing a good performance of traditional triple helix elements, but less rich in terms of ICTs. Quadrant III, finally, shows two cities with potential for improvement along both dimensions'.

The extent to which the smartness of these cities can be said to stand up to the advanced Triple Helix is perhaps notable, in the sense that it is only equalled by the degree to which they can also be seen - on this count at least - to stand apart and fall short of that measure.

This serves to reiterate the key message drawn from the modified Triple Helix model offered in Figure 2: namely, the current absence of suitable policies means smart cities do not possess either the corporate strategies needed or academic leadership qualities required for communities participating in their development to meet the governance challenge the public formally recognise. In particular, the governance challenge that it formally recognises and Figure 3 account for as the contents of those assessments which measure their respective performances i.e. the smartness of cities based on the standards of strategic leadership laid down by the advanced Triple Helix.

As Leydesdorff and Deakin et al. (2011) point out, this 'standing apart and falling short', is something that offers a particularly critical insight into the development of smart cities, vis-a-vis the tendency which there is for the reflexive instability of the intellectual capital embedded in their social networks, cultural attributes and environmental capacities, to produce a 'creative slack'. To produce a creative slack that in this instance stands as an index of the knowledge which is generated from these networks, attributes and capacities being insufficiently strategic. Insufficiently strategic in the sense that any meta-stabilisation which this produces is not fundamental enough for communities to directly participate in such a process of wealth creation as part of democratic governance. That is, as part of democratic governance which is capable of opening up the urban neighbourhoods of city districts to an environmentally sustainable reconstruction able to 'tighten up', 'take the strain' and 'stretch matters'. Tighten up, take the strain and stretch matters, to the extent it becomes possible for such a transformation to demonstrate what the ecology of this regional innovation system contributes to the vitality of the knowledge economy (also see Deakin and Leydesdorff, 2013: 139-145).

\section{The governance challenge}

As Paskaleva $(2009,2011,2013)$ and Deakin (2010a, 2012b, 2011a, 2011b) note, in order to get beyond the rhetoric of cities that claim to be smart and properly stand up to the governance challenge which smart cities pose, it is necessary to not only survey the status of the cities that proclaim to be smart but also assemble the instruments by 
which to measure any such performance. Instruments that include the models; networks, analytical frameworks and metrics, which make it possible to measure the smartness of cities. Models, networks, analytical frameworks and performance measurements that in this instance do not present themselves as readily available, off-theshelf, user-ready knowledge products, but as instruments which need to be assembled, constructed and built before they can meet the governance challenge in hand.

However, having presented this in the form of the critical synthesis which the paper advances as a Triple Helix-inspired account of smart city development, the lingering concerns that are associated with such a construction lie with whether the cultural and environmental significance of the emerging innovation systems shall merely reproduce the status quo, or if the participatory governance of direct democracy will only serve to punctuate the divisions underlying civil society and inequalities surfacing in the knowledge economy. Here concerns linger over the adverse effects that any such fault line within the constitution of smart cities, their regional innovation systems, transnational manifestation and global extension have on communities already caught in the digital divide and which their reconstruction as the urban neighbourhoods of city districts aim to bridge.

\section{Results and Discussion}

Based on this, it is evident that while the contributions from the future Internet development thesis and Triple Helix model do much to allay many of the fears surrounding the logic of leading corporate marketing campaigns, anxieties about the social capital, cultural attributes and environmental capacities of the technological possibilities smart cities offer still remain. For it appears that the degree to which the accumulation of social capital and deployment of intelligence their networks embed and in turn draw upon to cultivate future Internet developments, is seen as being sufficient to undercut the market economics of entrepreneur-driven business models, is a matter that many (for example, Paskaleva, 2013) still consider to be left 'in the balance'. Given the absence of any methodology supporting the future Internet's call for smart cities to be based on citizen-led co-creation, statements about the value of what the business models underlying such reconstructions contribute to the 'welfare and well-being' of regional innovation systems probably work best to highlight the true nature of the governance challenge these pose.

This is because such statements still illustrate a tendency to be overloaded with normative intent, unable to reveal where the integration of any such innovations can systematically open up the spaces needed for the urban neighbourhoods of city districts to be smart. For despite all of their ground breaking features, such accounts of smart cities do not currently cultivate the attributes that are needed for them to participate in the governance of this reconstruction as an exercise in direct democracy, let alone the environmental capacities which are also required to sustain any such process of wealth creation (Deakin et al. 2014).

In the absence of such evidence, the accounts of such reconstructions currently take on the status of meta-narratives and in that sense a 'mise-en-scene', which lack not only the principles but also intermediate concepts needed for the intelligence they currently possess to systematically evolve as innovations capable of being scaled-up to the size, weight and extent required. In particular and in this instance, as innovations not only able to create wealth on the standard called for but also as a measure of the cultural attributes and environmental capacities that communities need for cities to be smart 
when escalating their ICT-related developments in a manner which reflects the type of citizen-led change pioneers of this kind expect. For in order to demonstrate such an escalation and do so as a standard measure of wealth creation, it is not so much agendas which are needed, but models that are required. Models that are in turn able to systematically capture the true significance of such future Internet developments (i.e. in terms of both the extent, weight and size they amass) and represent this as a standard measure of the value, these technologies offer communities to be smart.

The reason for the slack we currently witness can perhaps best be explained by the tendency for future Internet developments to undercut the value of social networks, the intelligence they embed, cultural attributes this underpins and environmental capacities they, in turn, support as a standard measure of wealth creation. The tendency, that is, which they display to undercut all of this and instead represent smart city developments as the ecology of a predominately technological experience that offers the means by which to shore up the vitality of the knowledge economy.

The representation of the advanced Triple Helix set out here does not succumb to this tendency. It instead does not play on the idea of an ecosystem as something which naturally aligns with the economic but instead represents it as social phenomena that serve to underpin the networking of the intelligence smart cities embed, cultural attributes and environmental capacities which these in turn support. Which these attributes and capacities in turn support for the simple reason they serve as a means to 'offer up' the 'wealth of creative powers' that communities need to cultivate the type of future Internet developments cities embark on to be smart. That cities embark on to be smart in the sense which the type of environmentally sustainable reconstruction future Internet developments open up the opportunity for and make possible, not only serve the ecology of urban communities as city districts, but as the very means for this regional innovation system to hold such transformations up as a vital sign of the knowledge economy.

\section{Conclusions}

In addressing the governance challenge smart cities pose, this paper has subjected state-of-the-art accounts to a critique and drawn upon the synthesis this produces to advance a Triple Helix model able to overcome the limitations of both the smart city ranking and future Internet accounts of their development.

The model of smart cities advanced in this paper overcomes these limitations by not only configuring but also assembling the informational basis of a communication system whose recursive nature manages to transcend the reflexive instability associated with the 'statesman', 'corporatist' and 'laissez faire' idioms of knowledge production. Something which this Triple Helix model of smart cities manages to achieve by founding the informational basis of this communication system on the logic of a 'third mission' research agenda that captures the quintessentially civic value of knowledge produced in locally specific contexts.

In capturing the quintessentially civic value of the locally specific knowledge produced from this bottom-up exercise, the advanced Triple Helix model offers cities the prospect of being smart by turning the reflexive instability they currently experience to their advantage. That is, by doing nothing less than seizing the opportunity which the 
instability of this meta-stabilisation offers the academic community to reflect on how such government-led agendas can bootstrap the notion of smart cities by capitalising on the wealth of potential ICT-related developments offer to create value.

The capacity this Triple Helix model has to process such a socially inclusive, culturally diverse and environmentally sustainable reconstruction of cities reflexively; that is, in terms of translations which form part of a meta-stabilisation, is what marks this process of knowledge production out as a ICT-related development that is smart in the sense which it moves wealth creation beyond the dismantling of national systems and construction of regional advantages and in the direction of the local. In that, it moves wealth creation beyond the impasse of this systematic dismantling and construction of advantage and onto a platform which points in the direction of a local milieu. Onto a platform that points in the direction of a local milieu and which in turn embeds the intelligence, cultural attributes and environmental capacities that cities need to be smart when promoting ICT-related developments which champion the Internet.

In particular, in the direction of those attributes and capacities which are needed for universities and industry to champion the future Internet as ICT-related developments that open up the urban neighbourhoods of city districts to a participatory governance whose exercise in direct democracy is itself seen as being smart. Whose exercise in direct democracy is itself seen to be smart in terms of the underlying environmentally sustainable reconstruction this platform supports but which as yet is insufficiently strategic to shore up the third mission agenda that such a government-led meta-stabilisation advances. That is, shore up the third mission agenda which such a government-led metastabilisation advances to pick up the creative slack and be sufficiently fundamental for such an environmentally sustainable reconstruction to carry the full weight of scientific and technical expectation. In that sense, be sufficiently fundamental for such an environmentally sustainable reconstruction to carry the full weight of scientific and technical expectation by revealing what it is about this meta-stabilisation which not only underpins the ecology of urban communities as city districts but that is also equally strategic in supporting the very means which make it possible for regional innovation systems to hold these particular transformations up as a vital sign of the knowledge economy.

\section{Additional file}

Additional file 1: Multilingual abstracts in the five official working languages of the United Nations and Portuguese.

Competing interests

The author declares that he have no competing interests.

Received: 5 February 2014 Accepted: 1 July 2014

Published online: 21 November 2014

References

Caragliu A, Del Bo C, Nijkamp P (2011) Smart cities in Europe. Journal of Urban Technology 16(2):65-82

Caragliu A, Del Bo C, Nijkamp P (2013) Smart cities in Europe. In: Deakin M (ed) Smart cities: governing, modelling and analysing the transition. Routledge, Oxon

Cruickshank P (2011) SCRAN: the network. Journal of Urban Technology 18(2):83-97

Deakin M (2010a) A review of city portals: the transformation of service provision under the democratization of the fourth phase. In: Reddick C (ed) Politics, democracy and e-government: participation and service delivery. |G|, Hershey 
Deakin M (2010b) SCRAN's development of a trans-national comparator for the standardisation of e-government services. In: Reddick C (ed) Comparative e-government: an examination of e-government across countries. Springer Press, Berlin

Deakin M (2011a) The embedded intelligence of smart cities. International Journal of Intelligent Buildings 3(2):189-187

Deakin M (2011b) From the city of bits to eTopia: space, citizenship and community as global strategy in the governance of the digitally-inclusive regeneration strategy. In: Piaggesi D, Sund K, Castelnovo W (ed) Global strategy and practice of e-governance: examples from around the world. IGI Publisher, Hershey

Deakin M (2012a) Intelligent cities as smart providers: CoPs as organizations for developing integrated models of e Government Services. Innovation: The Journal of Social Research 23(2):115-135

Deakin M (2012b) SCRAN: assembling a community of practice for standardizing the transformation of e-government services, In: Aikins S (ed) Managing e-government projects: concepts. Issues and Best Practices, ICl Publisher, Hershey

Deakin M (ed) (2012c) Creating smart-er cities. Routledge, Oxon

Deakin M (ed) (2013) Smart cities: governing, modelling and analysing the transition. Routledge, Oxon

Deakin M, Al Waer H (2011) The transition from intelligent to smart cities. International Journal of Intelligent Buildings 3(2):140-152

Deakin M, Leydesdorff L (2013) The triple helix of smart cities: a neo-evolutionist perspective. In: Deakin M (ed) Smart cities: governing, modelling and analysing the transition. Routledge, Oxon

Deakin M, Lombardi P, Cooper I (2011) The IntelCities CoP for the capacity-building, co-design, monitoring and evaluation of eGov services. Journal of Urban Technology 18(2):17-38

Deakin M, Campbell F, Reid A (2014) Manchester as a digital powerhouse: governing the ICT-related developments. Measuring E-government Efficiency, Public Administration and Information Technology 5:91-212

Etzkowitz H (2002) The Triple Helix of university-industry-government: implications for policy and evaluation. Science Policy Institute, Stockholm

Etzkowitz H (2008) The Triple Helix: university-industry-government innovation in action. Routledge, Oxon

Freeman C (1995) The national system of innovation in historical perspective. Camb J Econ 19:5-24

Giffinger R, Kramar H, Haindl G (2008) The role of rankings in growing city competition. XI EURA Conference, Milan

Hollands R (2008) Will the real smart city please stand up? City 12(3):302-320

Komninos N, Pallot M, Schaffers H (2013) Special issue on smart cities and the future internet in Europe. Journal the Knowledge Economy 13(2):119-134

Kourtit K, Deakin M, Caragliu A, Del Bo C, Nijkamp P, Lombardi P, Giordano S (2013) An advanced triple helix network framework for smart city performance. In: Deakin M (ed) Smart cities: governing, modelling and analysing the transition. Routledge, Oxon

Leydesdorff L, Deakin M (2011) The triple helix of smart cities: a neo-evolutionary perspective. Journal of Urban Technology 18(2):53-63

Lombardi P, Giordano S (2012) Evaluating the European smart cities visions of the future. International Journal of the Analytic Hierarchy Process 4(1):27-40

Lombardi P, Del Bo C, Calagliu A, Deakin M, Nijkamp P (2011) An advanced Triple-Helix network model for smart cities performance in Ercoskun, O. In: Green and ecological technologies for urban planning. ICI Publisher, Hershey

Lombardi P, Giordano S, Farouh H, Yousef W (2012) Modelling the smart city performance. Innovation: the European Journal of Social Science Research 25(2):137-150

Nijkamp P, Kourtit K (2011) Urban Europe Joint Programme Initiatives. Free University, Amsterdam

Paskaleva K (2009) Enabling the smart city: the progress of city e-governance in Europe. International Journal of Innovation and Regional Development 1(4):405-422

Paskaleva K (2011) Smart cities: a nexus for open innovation? Intelligent Buildings International 3(3):153-171

Paskaleva K (2013) Smart cities: a nexus for open innovation? In: Deakin M (ed) Smart cities, governing, modelling and analysing the transition. Routledge, London

Porter M (1990) The competitive advantage of nations. Free Press, New York

Schaffers H, Komninos N, Pallot M, Trousse B, Nilsson M, Oliveira A (2011) Smart cities and the future Internet: towards cooperation frameworks for open innovation. In: Domingue J et al. (ed) Future internet assembly. LNCS, vol 6656, pp 431-446

doi:10.1186/s40604-014-0007-9

Cite this article as: Deakin: Smart cities: the state-of-the-art and governance challenge. Triple Helix 2014 1:7.

\section{Submit your manuscript to a SpringerOpen ${ }^{\circ}$ journal and benefit from:}

- Convenient online submission

- Rigorous peer review

- Immediate publication on acceptance

- Open access: articles freely available online

- High visibility within the field

- Retaining the copyright to your article

Submit your next manuscript at $>$ springeropen.com 